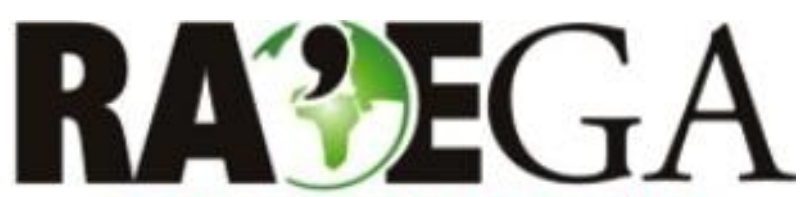

O ESPAÇO GEOGRÁFICO EM ANÁLISE

\title{
RESÍDUOS SÓLIDOS NA ÁREA URBANA DE FAZENDA RIO GRANDE/PR: A PRODUÇÃO SOCIOAMBIENTAL DO ESPAÇO URBANO NA CIDADE PERIFÉRICA
}

\section{SOLID WASTE IN URBAN AREA OF FAZENDA RIO GRANDE: PARANÁ -BRASIL: SOCIAL ENVIRONMENTAL PRODUCTION OF URBAN SPACE IN THE PERIPHERIC CITY}

\begin{abstract}
João Batista Alves ${ }^{1}$, Francisco de Assis Mendonça ${ }^{2}$, Rafaela Pacheco Dalbem ${ }^{3}$
RESUMO

Este trabalho analisa a produção e o uso do espaço urbano e a disposição de resíduos sólidos em espaços abertos da cidade de Fazenda Rio Grande-PR. Realizou-se um diagnóstico de toda a cidade. Os locais de deposição foram identificados por coordenadas geográficas, o que culminou na produção de mapas em Software ArcGIS. Verificou-se que todas as ruas da cidade estavam tomadas por disposição de resíduos em locais inadequados, como calçadas, ruas e terrenos vagos. Nas áreas de maior densidade populacional, há uma maior deposição de lixo. Em menor escala, ocorre o mesmo fato em setores censitários de menor renda. Essas condições denotam uma falha nos processos de gestão pública e da própria sociedade em lidar com seus resíduos, submetendo toda a comunidade a constantes riscos socioambientais. O estudo evidencia um exemplo da urbanização corporativa que se desenvolve nas cidades da periferia no capitalismo globalizado.
\end{abstract}

Palavras-chave: Cidade; Resíduos Sólidos; Uso do Solo; Espaço Urbano.

\section{ABSTRACT}

This paper analyzes the construction and use of an urban space, as they relate to the dispose of solid waste in open spaces in Fazenda Rio Grande - PR, Brazil. For this, conduct an overall diagnosis in the area. Wastelands have been identified by geographical coordinates and plotted in graphs with ArcGIS Software. It became evident that all over the town, streets were filled with waste deposits placed inappropriately along sidewalks, passageways and vacant lots. Moreover, in areas of high population density, there was a greater waste disposal. To a lesser extent, the same situation occurs in censitary sectors of the population with lower income. Such conditions indicate a failure in the processes of public management and society itself in handling their waste properly and, therefore, the entire community is constantly under socio-environmental risks. This paper shows an example of a corporative urbanization that process in a peripheric city of the capitalism context.

Key-words: City; Solid waste; Land use; Urban space.

Recebido em: 23/08/2016

Aceito em: 15/02/2017

\footnotetext{
${ }^{1}$ Universidade Federal de Campina Grande, Campina Grande/PB, e-mail: alvesjb@uol.com.br

${ }^{2}$ Universidade Federal do Paraná, Curitiba/PR, e-mail: chico@ufpr.br

3 e-mail: rafapdalben@hotmail.com
} 


\section{RESÍDUOS SÓLIDOS NA ÁREA URBANA DE FAZENDA RIO GRANDE/PR: A PRODUÇÃO SOCIOAMBIENTAL DO ESPAÇO URBANO NA CIDADE PERIFÉRICA}

\section{INTRODUÇÃO}

A produção do espaço urbano é marcada, na contemporaneidade, por uma série de externalidades socioambientais negativas, advindas, na sua essência, do modelo econômico hegemônico da modernidade. Ela revela, em determinadas particularidades locais, aspectos comuns ao jogo de relações de poder que se estruturam na ordem da macroescala, ou seja, da globalização.

Segundo a United Nations Organization - ONU (2011), grande parte da humanidade vive em ambiente urbano, com os percentuais assim distribuídos: América do Norte, 82\%; América Latina e Caribe, $80 \%$; Europa, 73\%; Oceania, 70\%; Ásia, 42\% e África, $40 \%$. Esses dados ajudam, assim, a entender a contribuição do processo de aglomeração urbana na geração de resíduos sólidos.

Como observado, uma das manifestações das relações entre sociedade e natureza, responsável por grande interferência daquela sobre esta, é o processo de urbanização intensa, amplificada pelo modelo hegemônico de produção capitalista, culminando com os processos de metropolização e periferização nas grandes cidades. Para entender estes fenômenos, primeiramente é necessário compreender o conceito de metrópole. Para Firkowski,

\footnotetext{
não são fenômenos recentes na história urbana, a etimologia da palavra nos remete à Grécia antiga, quando a mesma era utilizada para se referir a uma cidade mãe de outras, mãe no sentido de que essa grande cidade - a metrópole, tinha funções das quais dependiam as demais cidades. A metrópole estava, assim, relacionada ao domínio de um território, a oferta de bens e serviços diferenciados para uma região. (FIRKOWSKI, 2011, s.p.).
}

Para a autora, este processo vem sendo atualizado. $O$ que mudou, na contemporaneidade, foi a complexidade das funções das cidades, que passam a ser múltiplas, ao concentrar em atividades de comando e controle, ao mesmo tempo oferecendo uma série de serviços, e ao articularem relações entre redes de cidades regionais às globais.

Já a metropolização é definida por Ascher (2010, p. 62) como "a busca da concentração de riquezas humanas e materiais nas aglomerações mais importantes". Afirma ainda o autor que ela ocorre em diversos países, é diferente para cada região, sendo fruto "da globalização e do aprofundamento da divisão do trabalho em escala mundial, que tornam necessárias e mais competitivas as aglomerações urbanas".

Por outro lado, a aglomeração em grandes cidades leva a processos como o da periferização ${ }^{4}$. Davis (2006) aponta que, "nas cidades de crescimento desordenado do terceiro mundo, periferização é um termo extremamente relativo e específico de um momento: a orla urbana de hoje, vizinha de campos, florestas ou desertos, pode amanhã tornar-se parte de um denso núcleo metropolitano" ${ }^{5}$ (DAVIS, 2006, p.47).

Vale salientar que este processo de periferização tem características distintas a depender da época e do local. $\mathrm{Na}$ contemporaneidade, essas distinções são ainda maiores, e pode-se notar a predominância de duas delas: aquelas de alguns países denominados desenvolvidos, onde a periferização atual se dá envolvendo as classes mais privilegiadas, como os subúrbios ocupados por camadas de mais alta renda, nos Estados Unidos, como frisa Gottdiener (2010), e aquelas dos países do terceiro mundo, ocupadas por imensas orlas de favelas, conforme se compreende pelas formulações de (DAVIS, 2006).

Referindo-se ao país, Villaça (2001) menciona que uma característica comum de todas as metrópoles brasileiras está na

\footnotetext{
${ }^{4}$ Sobre periferia, ver : Moura e Utramari (1996).

${ }^{5} \mathrm{O}$ autor não chega a definir periferização, mas fica subentendido o conceito com as pesquisas desenvolvidas ao longo do texto daquele autor.
} 


\section{RESÍDUOS SÓLIDOS NA ÁREA URBANA DE FAZENDA RIO GRANDE/PR: A PRODUÇÃO SOCIOAMBIENTAL DO ESPAÇO URBANO NA CIDADE PERIFÉRICA}

periferização ${ }^{6}$, processo de formação do espaço urbano caracterizado por uma área central, bem atendida de toda infraestrutura urbana, onde se concentra a elite, e outra área oposta, cuja infraestrutura e equipamentos urbanos diminuem à medida que ocorre o afastamento espacial do grande centro da metrópole.

Para Santos (2005), o processo de periferização ${ }^{7}$ das cidades brasileiras decorre, em grande parte, da atuação política, uma vez que o próprio poder público se torna criador privilegiado de escassez do solo urbano para as camadas de baixa renda. Com isso, estimula e fomenta a produção de espaços vazios dentro das cidades e, ao tornar-se incapaz de resolver o problema da habitação social, empurra a maioria da população para as periferias. Empobrece ainda mais os mais pobres, forçados a suportar elevados custos, pelos precários transportes coletivos, e a comprar, a um preço caro, bens de consumo indispensáveis e serviços essenciais que o poder público não é capaz de lhes oferecer. Este fundamento é corroborado por Villaça (2001). Deste mesmo contexto, pode-se extrair a conclusão de que as cidades contemporâneas se constituem "num dos principais fenômenos a explicitar de maneira clara as contradições da modernidade e, portanto, a evidenciar as contradições de classe que tão fortemente marcam a sociedade capitalista no seu estágio mais avançado", conforme ressalta Mendonça (2004, p. 192).

Em síntese, uma das manifestações máximas da sociedade capitalista de consumo ${ }^{8}$ é o fenômeno da metropolização, que submete populações ao processo de exclusão econômica e social, "criando" massas enormes de pessoas com baixo nível de renda, escolaridade precária

\footnotetext{
${ }^{7}$ Ver, também: Moura e Ultramari (1996).

${ }^{8}$ Com base em Pereira e Simioni (2010, p. 38), podese entender esta sociedade como aquela que "[...] o consumo passa a desempenhar um critério de distinção, uma forma de produção de sentido. 0 consumo passa a constituir papéis sociais, passa a constituir campos simbólicos dentro dos quais são mantidas redes de significação social".
}

ou inexistente. Isso faz com que essas populações ocupem as periferias das cidades, onde se tornam passíveis de toda má sorte de condições de sobrevivência, por morarem, muitas vezes, em áreas de risco. Esta situação leva as pessoas a tornarem-se vulneráveis a um amplo conjunto de mazelas, resultado das condições precárias que lhes são oferecidas pelo ambiente para onde são empurradas. Correm então riscos de adoecer, pelas condições de insalubridade verificada na água poluída e contaminada por resíduos líquidos e sólidos, vetores transmissores de doenças, entre outros.

O entendimento de como ocorre o uso do solo, em especial nos ambientes urbanos, onde habita a maior porção da população mundial na atualidade, é fundamental para se compreenderem os efeitos de tais externalidades. Constituindo-se numa produção social, o espaço geográfico pode ser definido como um conjunto indissociável de sistemas de objetos e sistema de ações (SANTOS, 2006), que acabam determinando a dinâmica de seu uso e ocupação. É no ambiente urbano que estes processos ocorrem de forma mais intensa e, portanto, onde emergem, de modo mais drástico, as externalidades conferidas hoje por aquilo que Rodrigues (1998) e Mendonça (2004) concebem como sendo a problemática socioambiental urbana.

Dentre as inúmeras problemáticas socioambientais urbanas, destaca-se a dos resíduos sólidos, visto que, segundo Waldman (2010) "obras de engenharia como aterros sanitários, [...] incineradores e depósitos de sucata, comuns em muitos centros urbanos, são vetores de uma movimentação apoiada pela oferta incessante de resíduos urbanos". Outra variável é aquela referente aos lixões: "áreas de descarte indiscriminado de resíduos [...] representação emblemática do descaso dos poderes constituídos por suas áreas de periferia, tais espaços são, em várias cidades do terceiro mundo, apropriados por levas de imigrantes pobres" (WALDMAN, 2010, p. 17). Para ele, o conceito é polêmico, pois 


\section{RESÍDUOS SÓLIDOS NA ÁREA URBANA DE FAZENDA RIO GRANDE/PR: A PRODUÇÃO SOCIOAMBIENTAL DO ESPAÇO URBANO NA CIDADE PERIFÉRICA}

de um ponto de vista semântico, podemos certificar que lixo seria todo material inútil, todo material descartado posto em lugar público, tudo aquilo que 'se joga fora', 'não presta', condição à qual são evocadas longas catilinárias devotadas à nocividade, periculosidade, intratabilidade etc. 0 enunciado de lixo enquanto substância desprezada pode ser confirmado quando avaliamos a etimologia da palavra - isto é, sua origem e significação da história. As palavras rubbish, waste, trash, junk e gabage incluem este sentido. 0 mesmo ocorre com as termos abfall, mull e kehricht na língua alemã. De igual modo, basura, em castelhano; déchet, em francês; refiuti em italiano e residu, em catalão, repetem esta significação". "Em português, a origem da palavra lixo é controvertida. Aparentemente procede de lix, palavra latina que significa cinza ou lixivia. A lix associa-se o verbo lixare reportando a polir, arrancar o excedente. (WALDMAN, 2010 , p. 18 , grifos do autor)

Na sua perspectiva, contudo, a noção de restos está vinculada a contextos históricoculturais que, associados a dinâmicas sociais, não podem ser aferidos somente a partir de critérios objetivos; transcendem signos materiais, "porque a construção da percepção do lixo é amiúde endossada por modelos imaginários, indispensáveis para a compreensão de variado leque de nuanças relacionadas como os resíduos". Também Jacobi $(2012$, p. 31) discorre que, para "refletir sobre os resíduos sólidos urbanos, é necessário levar em conta aspectos espaciais, ambientais, de saúde, sociais, culturais e institucionais". Corrobora Waldman (2010), ao asseverar que, em diferentes contextos culturais, existem diferentes modos de percepção do que é lixo e seu respectivo gerenciamento.

Rodrigues (1988), por seu turno, enfatiza que a problemática do lixo na contemporaneidade está criando novos territórios indesejáveis ou segregados, ou seja, as áreas onde são dispostos os mais diversos tipos de resíduos. Os mesmos fazem parte do que a autora denominou de intercâmbio ecologicamente desigual, que ocorre entre regiões, países etc., podendo ocorrer até mesmo em uma cidade, "como é o caso dos depósitos de lixo doméstico, que devem ser situados cada vez mais longe e que têm servido para a sobrevivência dos mais pobres que coletam os restos". A mesma autora indica, ainda, que, "nas informações mais gerais divulgadas pelos meios de comunicação de massa -, parece que apenas uma fração da população é altamente poluidora (a mais pobre), pois desmata para comer, mora perto de lixo ou não cuida do lixo, da higiene, etc." (RODRIGUES, 1988, p. 79-102). Os mesmos meios midiáticos apontam o consumidor final como o responsável pela poluição, não importando a classe social.

Dentre esses espaços indesejáveis abordados pela literatura, estão os aterros sanitários, os lixões, os depósitos de lixo tóxico etc. Podem-se somar a estes os resíduos dispostos a céu aberto, ou seja, em espaços livres das áreas urbanas e rurais, em especial, nos países emergentes e nos não desenvolvidos, aspectos reveladores da urbanização corporativa (SANTOS, 2005) que se processa na periferia do sistema. A literatura que trata desta questão é bastante farta, tanto no exterior quanto no Brasil, dentro da qual se destacam as contribuições de Figueiredo (1994) e Waldman (2010) no Brasil; Joseph (2002), Índia; Bonfanti (2004), Argentina; Reyes (2004), Cidade do México; Chiemchaisri et al. (2007), Tailândia; United Nations-Habitat (2006) em várias cidades ao redor do mundo; Yalana, L. et al.(2008), Pequim; Abul, S. (2010), Suazilândia; Bandara (2010), Sri Lanka; Jalil (2010), Malásia; Fazzo, L; Santis, M.; Mitis, F. et al.(2011), Itália; Mudzengerere, F. H.; Chigwenya, A. (2012), Zimbábue, etc.

O lixo disposto a esmo nas áreas urbanas pode levar as pessoas, que com ele tenham permanente contato, a inúmeros problemas de saúde física e mental, além dos problemas ambientais decorrentes, conforme demonstram diferentes publicações sobre esta 


\section{RESÍDUOS SÓLIDOS NA ÁREA URBANA DE FAZENDA RIO GRANDE/PR: A PRODUÇÃO SOCIOAMBIENTAL DO ESPAÇO URBANO NA CIDADE PERIFÉRICA}

temática; dentre estas, destacam-se Geschwind et al. (1992), Secretaria Especial de Desenvolvimento Urbano da Presidência da República - SEDU (2001), Lima (2001), Ferreira e Anjos (2001), Nunesmaia (2002), Orsi (2002), Heller (2002), Muñoz (2002), Crowley et al.(2003), United Nations Environment Programme - UNEP (2006), Moraes (2007), Nakayama e Ohkuma (2006) e Thompson e Anthony (2008)

O processo da construção social do espaço leva ao uso e ocupação do solo das mais diversas formas; nos países não desenvolvidos, constituem o tipo de urbanização corporativa (SANTOS, 2005) e, por conseguinte, emergem, na sua dinâmica de desenvolvimento, externalidades socioambientais negativas, dentre as quais, a problemática dos resíduos sólidos. Tal processo decorre, principalmente, do modelo de desenvolvimento moderno em situação de periferia do sistema capitalista globalizado, no qual as políticas públicas de ordenamento territorial e desenvolvimento urbano são "inexistentes, inócuas e/ou ineficazes", pois poucos tocam os problemas socioambientais e suas causas fundamentais que estão, em quase sua totalidade, "ligados à superestrutura da sociedade" (MENDONÇA, 2004, p. 192)

Por outro lado, pode-se também compreender a dinâmica dos resíduos sólidos a partir do entendimento do Sistema Ambiental Urbano e seus três subsistemas, conforme o Programa das Nações Unidas para o Desenvolvimento - PNUD (1997, p. 65). A problemática dos resíduos sólidos urbanos resulta em contaminação, deterioração e precariedade associadas à interação entre o ambiente social, o ambiente construído e o ambiente natural, controlados que são pelo consumismo, urbanização corporativa e gestão pública da cidade, como se pode constatar no esquema adaptado do PNUD/UNOPS, apresentado na Figura 1.

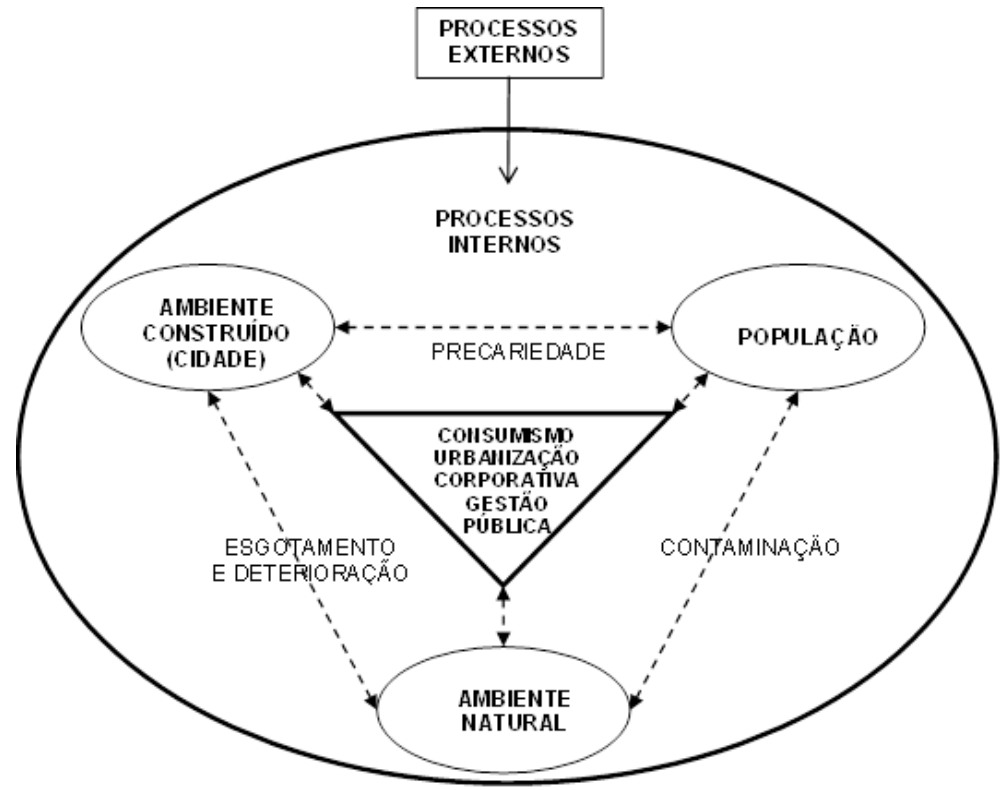

Figura 1 - Dinâmica da problemática ambiental urbana - resíduos sólidos espalhados em espaços abertos - Fazenda Rio Grande-PR. (2013). Organização: AUTORES DO TEXTO, adaptado de PNUD (1997, p. 65).

Nesse sentido, é imperativo que se conheçam as relações existentes entre o uso do espaço e a geração de resíduos em suas diversas interfaces. Para tanto, o objetivo do presente trabalho é analisar, a partir de um estudo de caso, a construção e o uso do espaço 


\section{RESÍDUOS SÓLIDOS NA ÁREA URBANA DE FAZENDA RIO GRANDE/PR: A PRODUÇÃO SOCIOAMBIENTAL DO ESPAÇO URBANO NA CIDADE PERIFÉRICA}

urbano associado à deposição de resíduos sólidos em espaços abertos da cidade de Fazenda Rio Grande, Região Metropolitana de Curitiba, no Estado do Paraná. A quantidade de resíduos sólidos urbanos espalhados em ruas, calçadas e lotes vagos/vazios na área urbana desta cidade é tão marcante que suscitou uma análise pormenorizada de sua ocorrência, como se verá no âmbito do presente texto.

\section{2. ÁREA DE ESTUdO E PROCEDIMENTOS METODOLÓGICOS}

O levantamento de dados foi realizado na cidade de Fazenda Rio Grande-PR (FRG), uma das cidades da Região Metropolitana de Curitiba (RMC) que mais tem recebido fluxos migratórios. Na década de 1990, registrou a maior taxa de crescimento populacional no Brasil, que, segundo o IPARDES (2006), foi superior a $10 \%$. Consta, pelos dados do IBGE (2010), uma população atual de 81.675 habitantes.

A produção de resíduos nesse município, segundo a Secretaria de Meio Ambiente, é de uma coleta aproximada média diária de 44,5 tn/dia, perfazendo uma geração de 0,545 kg/hab./dia. Esse volume corresponde a uma média bem abaixo daquelas verificadas nas coletas realizadas país afora, ou dentro do estado do Paraná e cidade de Curitiba, quando se compara com os dados informados pela Associação Brasileira de Empresas de Limpeza Pública e Resíduos Especiais - ABRELPE (2012).

Para a elaboração do estudo, os seguintes procedimentos metodológicos foram adotados:

Primeiramente procedeu-se ao mapeamento dos resíduos sólidos distribuídos aleatoriamente por toda a área urbana da cidade, tendo por base uma tipologia elaborada para a identificação dos mesmos e que foi aplicada a uma planta cadastral da cidade. A definição de quais tipos de resíduos seriam mapeados e qualificados teve como base as normas da ABNT-NBR 10004 (classificação de resíduos sólidos) e um trabalho piloto no qual se observaram, em vários pontos da cidade, quais os resíduos mais comuns depositados em terrenos e ruas de cada localização.

A análise dos conteúdos mais comuns dos resíduos levou à criação de planilhas de avaliação e tipificação próprias, categorizando os tipos de resíduos dispostos acima de $1 \mathrm{~m}^{2}$. Foram tipificadas 13 espécies de resíduos para o levantamento de campo e parte das análises e, posteriormente, foram agrupados em quatro classes baseadas nas normas da ABNT (NBR: 10004-2004; 12808-1993 e 12807-1993), exceção dos resíduos tipo Mix (denominação destes autores para expressar o que foi constatado em campo).

As quatro classes foram: Resíduos sólidos perigosos ( $R E L$ : resíduos eletrônicos, $R P$ : pilhas, baterias e lâmpadas de mercúrio); Resíduos sólidos perigosos saúde/biológicos ( $R S B-D O$ : fraldas e papel higiênico usado, RSB$H O$ : agulhas, bolsas de soro utilizado etc., RSBOUT: carcaças de animais em decomposição, $R S B-R E$ : remédios não utilizados e vencidos); Resíduos não perigosos ( $R L P$ : resíduos de madeira e podas de árvore e gramas, RDO: resíduos domésticos [secos] - plástico, roupas, vidros, papel, calçados etc., RCC: entulho de construção, RIC-CO: peças plásticas, metálicas, carcaças de carro, isopor advindos do comércio etc., RIC-IN: peças metálicas e de cimento armado, plásticas não identificadas) e Resíduos tipo MIX (restos de resíduos contendo pequenas amostras de vários tipos de resíduos, muitos dos quais foram submetidos à queima ao ar livre. Caracterizam-se por pontos contínuos de deposição de resíduos, sofrendo retiradas parciais ou queimas constantes classificação própria).

Para uma melhor representação da distribuição dos resíduos sólidos, foi feita uma sobreposição do mapa cadastral da cidade sobre uma imagem Google Earth, com base de dados georreferenciados pelo ParanaCidades. Para os resíduos de calçadas e ruas, eram tomadas as coordenadas geográficas (latitude e longitude) sistema SAD 69-22 UMT - América do Sul, com GPSMap 76CSx, marca Garmin. Os 


\section{RESÍDUOS SÓLIDOS NA ÁREA URBANA DE FAZENDA RIO GRANDE/PR: A PRODUÇÃO SOCIOAMBIENTAL DO ESPAÇO URBANO NA CIDADE PERIFÉRICA}

mapas foram todos produzidos no software ArcGIS10.

O mapa de concentração dos resíduos foi gerado através da Densidade de Kernel, uma das opções estatísticas do ArcGIS, através de pontos. Os pontos estariam locados espacialmente (por um par de coordenadas $x$, $y)$ e por meio de uma função bidimensional que contabiliza os pontos dentro de uma área específica. "O estimador de Kernel tem por objetivo gerar uma grade em que cada célula representa o valor da intensidade, densidade, razão entre atributos etc. O valor obtido será uma medida de influência das amostras na célula". (OLIVEIRA e SANTOS, 2011).

Por meio desse método estatístico, foi possível determinar os pontos de maior ou menor concentração de resíduos sólidos, levando-se em consideração a tipologia de resíduos. Os intervalos foram determinados pelos "natural breaks", que indicam quando há uma "quebra" na numeração e que o agrupamento de pontos dentro daquele intervalo é homogêneo.

Foram utilizados também os mapas de renda domiciliar e de densidade populacional por setor censitário no perímetro urbano de FRG, construídos a partir de dados do Censo do IBGE (2010). A análise comparativa entre os mapas de concentração de pontos de resíduos e indicadores sociais, renda e densidade populacional foi feita por sobreposição de mapas.

\section{RESULTADOS E DISCUSSÃO.}

A cidade de FRG tem cadastrados 24.310 lotes urbanos, sendo que $18,59 \%$ (4.519) são lotes vazios e/ou vagos. Desses, $55,34 \%$ estão contaminados por algum tipo de resíduo (detalhes em um setor da cidade Figura 2), ou seja, $10,29 \%$ do total de lotes. Já os resíduos encontrados em calçadas e ruas da cidade, acima de $1 \mathrm{~m}^{2}$, somam 3.552 focos (Figura 3). A partir deste último, formou-se o mapa de concentração de resíduos (Figura 4). Esse mapa foi comparado com outros dois de indicadores sociais: o de renda e o de densidade populacional (Figuras 5 e 6), ambos divididos por setor censitário, informações obtidas com base no Censo IBGE (2010).

Os quatro tipos de resíduos mais comuns encontrados foram aqueles incluídos na classe dos resíduos não perigosos e tipologia Mix, sendo nesta impossível de determinar se continha ou não resíduos além dos não perigosos. Para os resíduos dispostos em terrenos vagos em ordem decrescente de ocorrência, os focos estão assim distribuídos: resíduos de construção, 1.707; resíduos domésticos, 1.566; resíduos de limpeza pública, 1.497 e categoria Mix, 1.085. Para os resíduos depositados nas calçadas e ruas, a quantidade de focos por categoria é assim distribuída: resíduos de construção, 2.261; resíduos domésticos, 2.068; resíduos de limpeza pública, 2.040 e resíduos categoria Mix, 1.767. Embora em menor quantidade, houve ocorrência das outras categorias de resíduos classificados como perigosos, tanto aqueles provenientes de produtos eletroeletrônicos, como também de recipientes com materiais contaminantes como os patogênicos. 


\section{RESÍDUOS SÓLIDOS NA ÁREA URBANA DE FAZENDA RIO GRANDE/PR: A PRODUÇÃO SOCIOAMBIENTAL DO ESPAÇO URBANO NA CIDADE PERIFÉRICA}

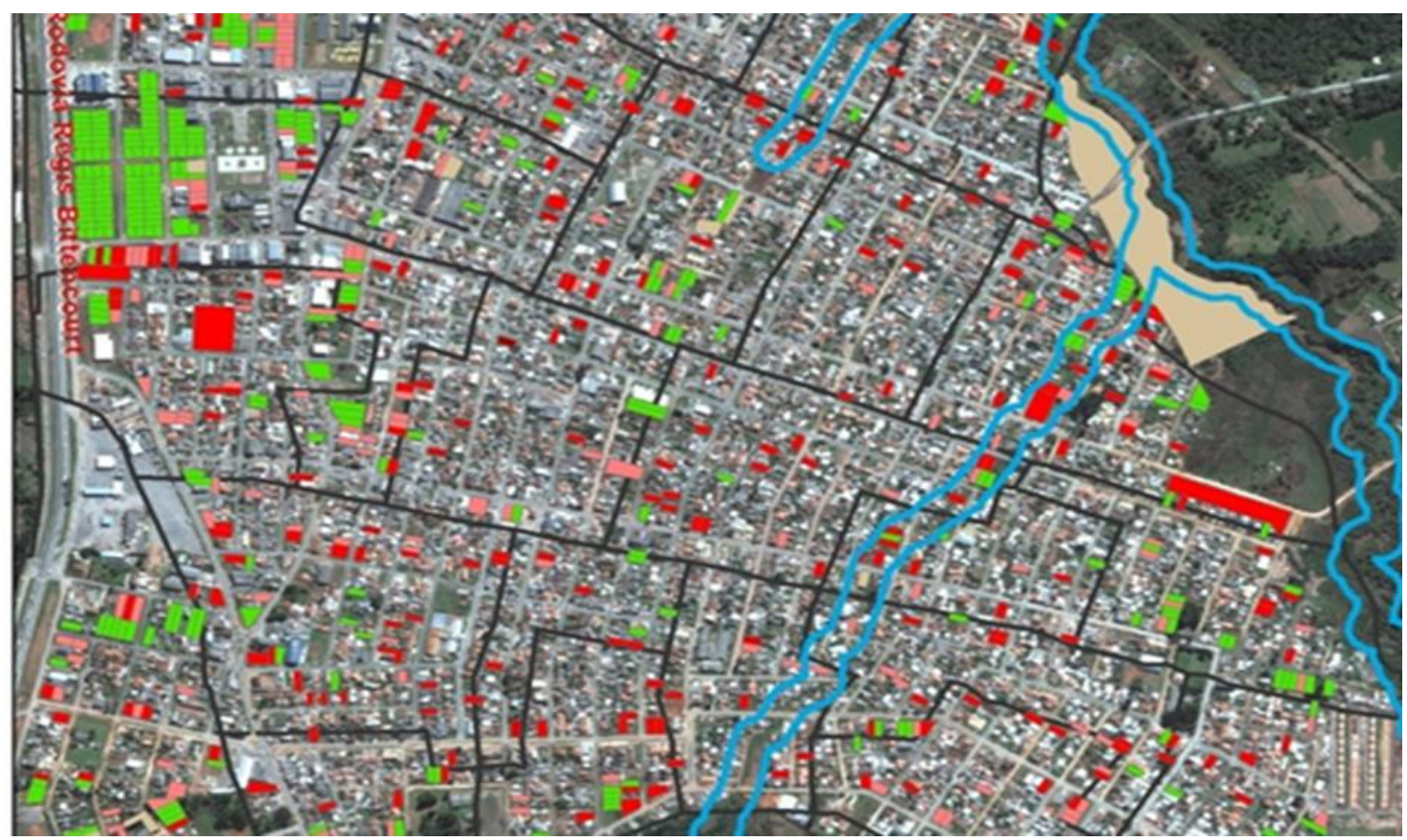

Figura 2 - Amostra de imagem de lotes vagos com resíduos sólidos (tons vermelhos). Fazenda Rio Grande - PR (2012).

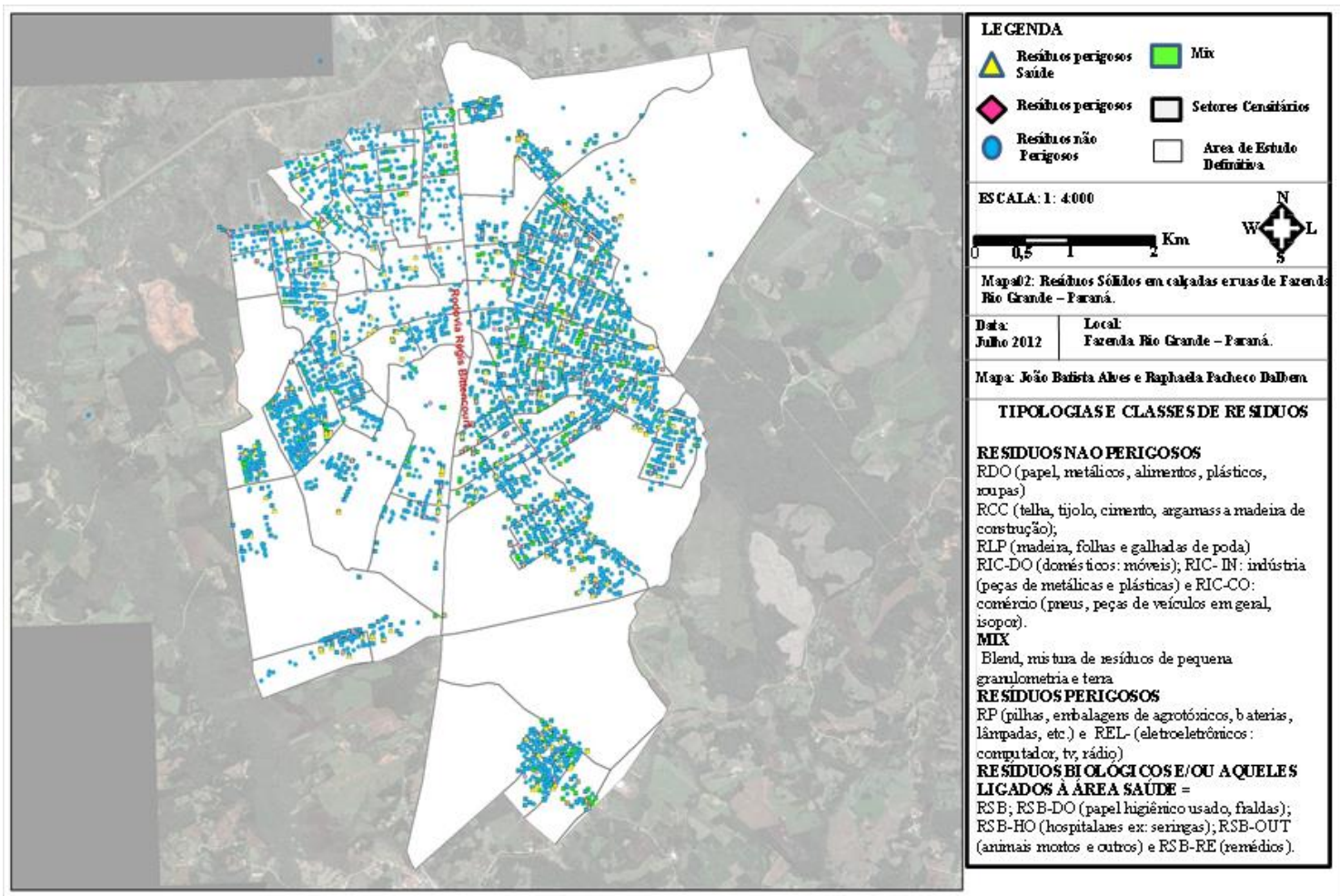

Figura 3 - Resíduos sólidos em calçadas e ruas. Fazenda Rio Grande - PR (2012). 


\section{RESÍDUOS SÓLIDOS NA ÁREA URBANA DE FAZENDA RIO GRANDE/PR: A PRODUÇÃO SOCIOAMBIENTAL DO ESPAÇO URBANO NA CIDADE PERIFÉRICA}

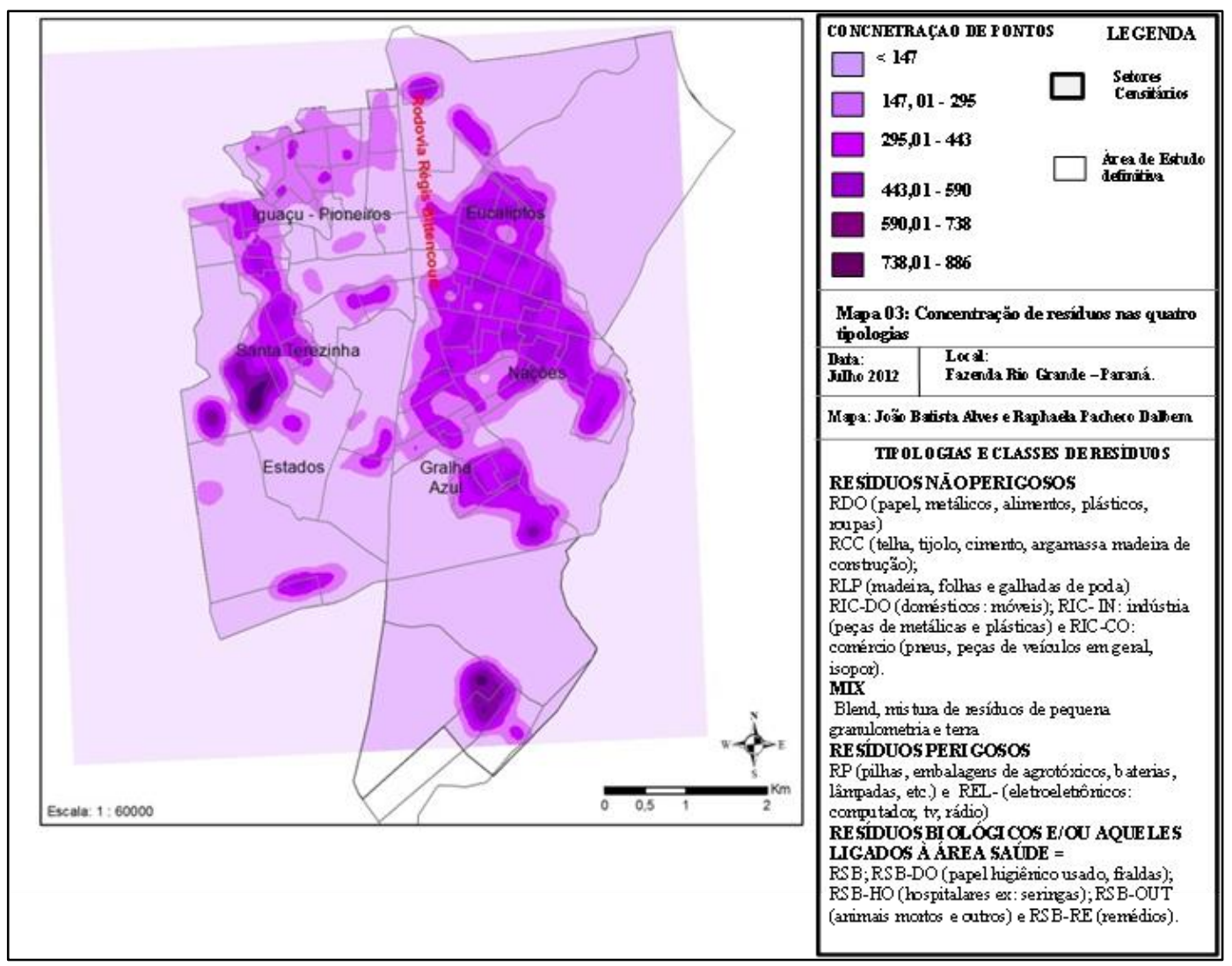

Figura 4 - Concentração de pontos de resíduos sólidos em calçadas e ruas Fazenda Rio Grande - PR. (2012).

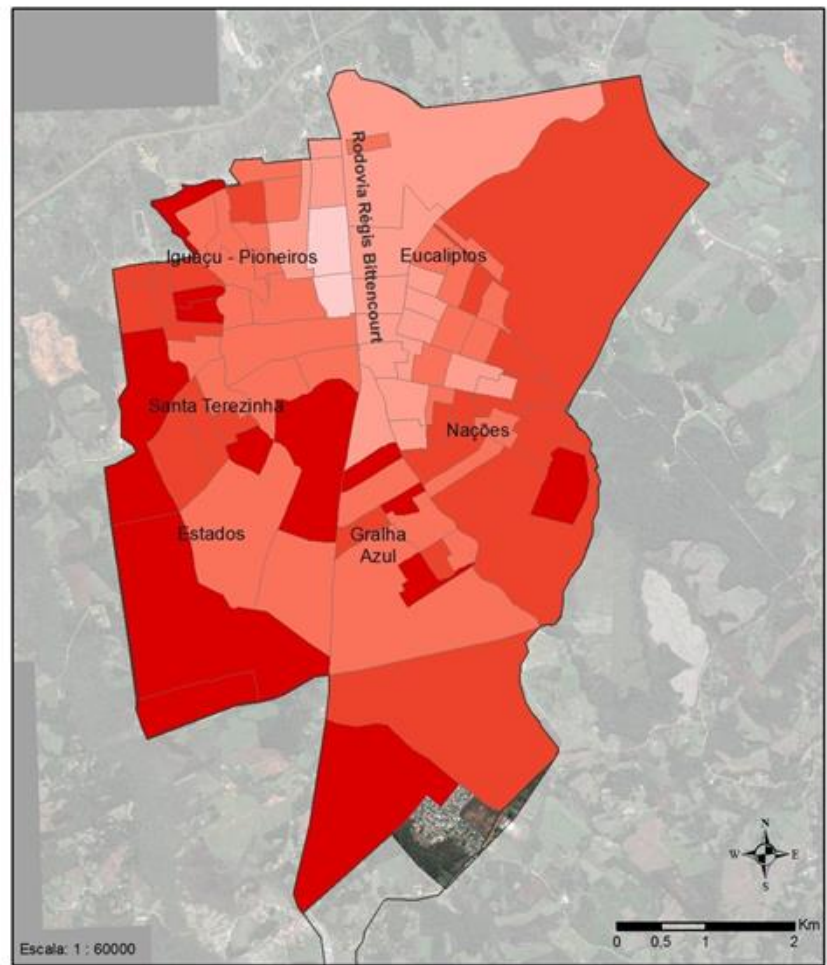

\section{Legenda}

Setores Censitários - IBGE2010

Renda Inferior a 1 Salário Mínimo - \%

$\square<28,5$

$28,51-51$

$51,1-60,5$

$60,51-69,5$

$\square>69,6$

Delimitaçâa da Área de Estudo

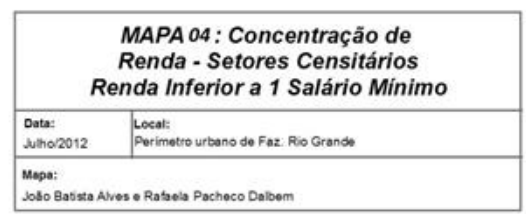

Figura 5: Mapa de concentração de renda por setor censitário. Fazenda Rio Grande-PR. (2012)

Figura 5 - Mapa de concentração de renda por setor censitário. Fazenda Rio Grande-PR. (2012). 


\section{RESÍDUOS SÓLIDOS NA ÁREA URBANA DE FAZENDA RIO GRANDE/PR: A PRODUÇÃO SOCIOAMBIENTAL DO ESPAÇO URBANO NA CIDADE PERIFÉRICA}
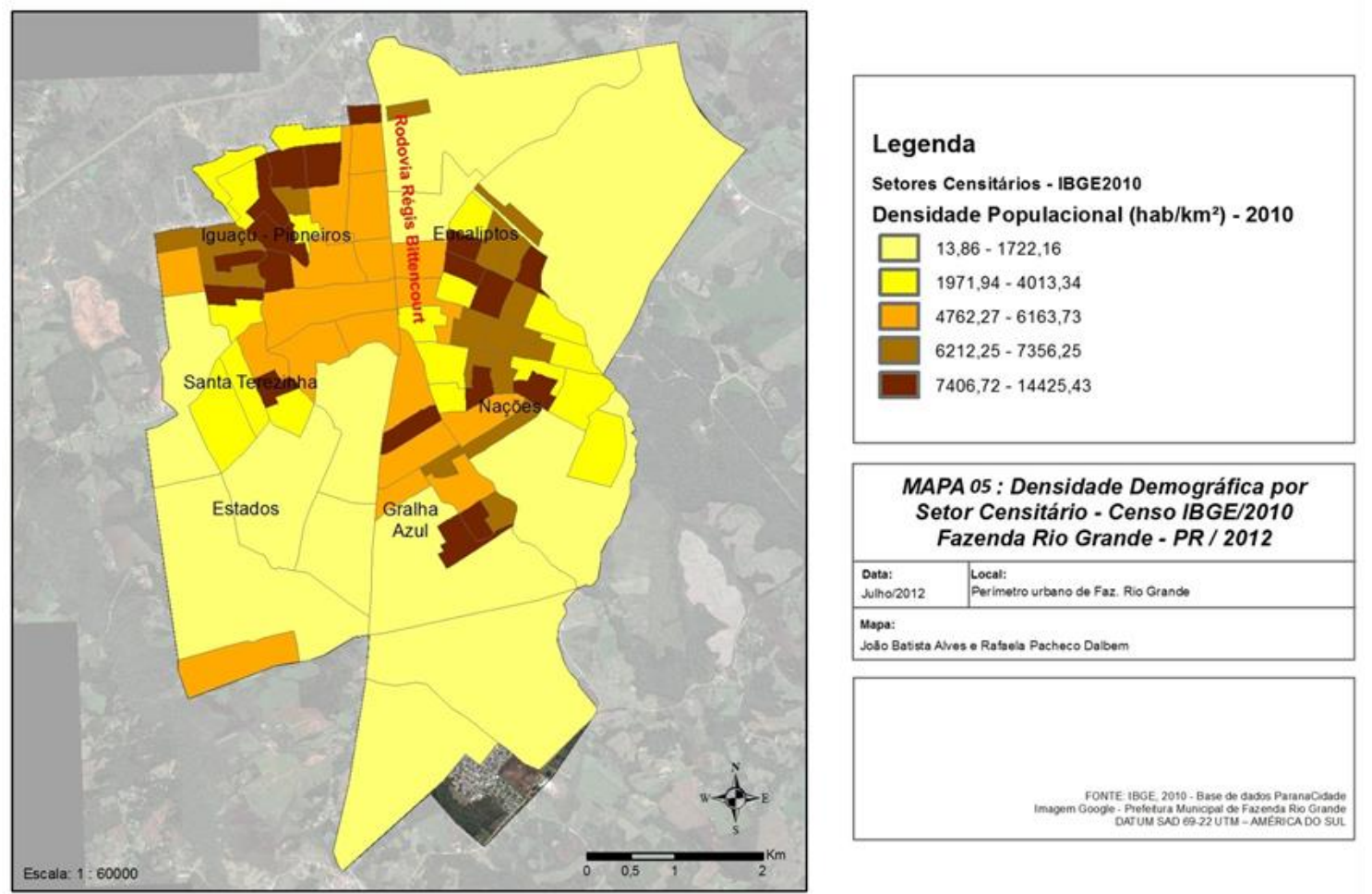

Figura 6: Mapa de densidade populacional. Fazenda Rio Grande-PR. (2012)
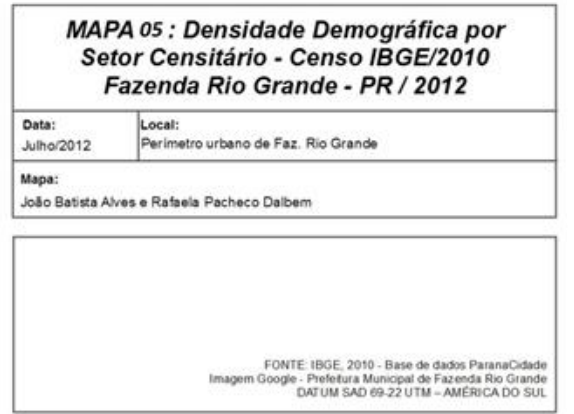

Figura 6 - Mapa de densidade populacional. Fazenda Rio Grande-PR. (2012).

$O$ que se verifica quanto a terrenos contaminados com resíduos é que há uma ampla distribuição deles por toda a cidade. Da mesma forma, observa-se, de uma forma geral, uma ampla distribuição de resíduos em calçadas e ruas em diversos setores da cidade.

Pelo mapa de concentração de pontos, contudo, verifica-se que há uma tendência de setores censitários de menor renda em concentrar mais resíduos (Figura 5). Por outro lado, há uma maior correlação entre densidade populacional e presença de resíduos em calçadas e ruas (Figura 6), ou seja, há uma maior correlação entre a presença de resíduos e densidade populacional, o que denota que toda a cidade está contaminada com resíduos, ora mais dispersos ora mais concentrados. Aqui se verifica realmente uma observação de Rodrigues (1998), de que, na questão do lixo, não importa a classe social e, embora a autora faça essa referência em outro sentido, o lixo em FRG está disposto a céu aberto em todos os locais da cidade, em maior ou menor concentração.
Apreende-se, por meio deste contexto, que as relações estabelecidas entre a sociedade local, o ambiente construído e o natural (Figura 1), que se manifestam na construção espaço urbano, uso e ocupação do solo, ocorrem de forma bastante precária. $O$ descaso das pessoas com o espaço público e com a própria sociedade (representada pelos proprietários dos terrenos privados) acarreta o sofrimento a toda a população, com os impactos socioambientais causados por essa situação.

A presença de resíduos, por si só, já é um problema pela atração e disseminação de vetores causadores de doenças, além da questão estética e dos conflitos de vizinhança gerados. Neste sentido, há a formação de espaços indesejados conforme indica Rodrigues (1998), fruto de uma sociedade que está entregue ao consumismo exagerado, em especial no Brasil, como assevera Rolnik (2012). Pode-se inferir que, em outros contextos nacionais onde isso ocorre, esta situação pode se manifestar da mesma maneira. 


\section{RESÍDUOS SÓLIDOS NA ÁREA URBANA DE FAZENDA RIO GRANDE/PR: A PRODUÇÃO SOCIOAMBIENTAL DO ESPAÇO URBANO NA CIDADE PERIFÉRICA}

Verifica-se que as regiões centrais da cidade, ao redor da rodovia Regis Bittencourt (BR 116), que corta a cidade no sentido nortesul (local onde a cidade teve origem e onde, também, se localizam o centro comercial e administrativo), são aquelas com uma grande quantidade de lotes vazios, bem como de menor incidência de resíduos. Ou seja, há uma preocupação maior com limpeza nessas localidades, tendo em vista a visibilidade proporcionada pela rodovia aos transeuntes; muito possivelmente, a sociedade local toma precauções para que a percepção da imagem associada à cidade seja a de uma cidade limpa.

Por outro lado, evidencia-se aquilo que Mendonça (2004) afirma sobre a inocuidade das políticas públicas no ordenamento territorial, o que culmina na falta de atenção ou menosprezo dos dirigentes da cidade para com os problemas socioambientais. Estes estão intrinsecamente ligados ao modelo de desenvolvimento econômico hegemônico da fase mais contemporânea da modernidade e que tem, na atualidade, um dos seus pilares assentados no consumismo, como asseveram tantos autores como Figueiredo (1994), Rodrigues (1998), Mendonça (2004), Bauman (2011), entre outros. Nesse sentido, tanto a grande presença de resíduos sólidos espalhados por toda a cidade, como também a existência de lotes vagos e/ou vazios, sem os devidos cuidados ou ocupação, evidenciam características de uma gestão ineficaz do uso e ocupação do solo.

As particularidades e repercussões do problema averiguado suscitam recorrer ao conceito de Santos (2006), aquele que concebe ser o espaço um conjunto de sistemas de objetos e de sistemas de ações determinantes da dinâmica de seu uso e ocupação. Verifica-se que os objetos (área construída e os próprios resíduos) e as ações (humanas) estão numa dinâmica desfavorável, tanto em termos ambientais como em termos sociais, tendo em vista a cidade se tornar insalubre, em consequência dos resíduos sólidos espalhados por toda a área urbana. Daí decorre a contaminação do solo e dos mananciais hídricos, dentre outros, sendo o prejuízo e a má qualidade de vida diretamente impactantes à população, posto que está em cotidiana convivência com os resíduos espalhados.

Por conta da deposição clandestina e inadequada dos resíduos em terrenos, ruas e calçadas, estes locais acabam se tornando fontes não somente de contaminações ambientais, mas de procriação de vetores causadores de doenças, em especial nas áreas mais periféricas, onde vivem as populações de mais baixa renda, como pode ser visto pelo mapa de renda. São elas, portanto, que estão, potencialmente, mais expostas aos maiores riscos, ao mesmo tempo em que estão mais vulneráveis aos diversos problemas associados, devido à menor disponibilidade de recursos financeiros e informações para resolver problemas de saúde e outros de natureza física, e até mesmo de conflitos. A literatura referida respalda a constatação de que toda a população da cidade de FRG está potencialmente suscetível a contrair doenças em função da realidade encontrada.

\section{CONSIDERAÇÕES FINAIS}

Verificou-se que a cidade de FRG tem cadastrados 24.310 lotes, sendo que 18,59\% (4.519) são lotes vagos. Desses, 55,34\% estão contaminados por algum tipo de resíduos, ou seja, $10,29 \%$ do total de lotes. Já os resíduos encontrados em calçadas e ruas da cidade, em áreas superiores a $1 \mathrm{~m}^{2}$, somam 3.552 focos. Os resíduos têm as mais diversas origens, predominando os não perigosos, mas há ocorrências de resíduos perigosos provenientes de produtos eletroeletrônicos e patogênicos.

A sociedade de Fazenda Rio Grande vem construindo seu espaço urbano de forma precária, o que se manifesta em uma ampla deposição de resíduos sólidos a céu aberto, espalhados a esmo por toda a superfície da área urbana. Isso denota potencialidade de inúmeros impactos socioambientais, destacando-se dentre aqueles relacionados à saúde pública, devido à sempre iminente 


\section{RESÍDUOS SÓLIDOS NA ÁREA URBANA DE FAZENDA RIO GRANDE/PR: A PRODUÇÃO SOCIOAMBIENTAL DO ESPAÇO URBANO NA CIDADE PERIFÉRICA}

contaminação dos habitantes, pela presença de vetores causadores de doenças, que, em considerável proporção, convivem nos ambientes deteriorados pela contínua presença de resíduos dispostos a esmo, como os lotes urbanos vazios, as calçadas e as ruas.

Depreende-se também que tanto a população urbana da cidade estudada quanto a administração local são responsáveis pelo problema identificado e analisado neste texto; no caso da primeira, ressalta-se a falta de comprometimento e de cidadania, o que impele a pensar no papel da educação ambiental como possível solução do problema através da participação. No caso da administração municipal, evidencia-se também o descaso com a esfera pública, ou seja, com a gestão responsável pela cidade, posto que permite a formação de situações cotidianas de insalubridade a toda a população da área urbana.

A problemática dos resíduos sólidos urbanos não é um caso particular da cidade de Fazenda Rio Grande, como se evidenciou ao longo do estudo; ela reflete, na escala local / municipal, um processo muito maior de produção e reprodução do espaço urbano no capitalismo, revelando uma particularidade da periferia do mesmo. A associação entre vários fatores (urbanização desenfreada e caótica, a exacerbação do consumismo, ausência de cidadania entre moradores e a débil gestão urbana) está na base da formação de situações como aquela que foi registrada numa das cidades da Região Metropolitana de Curitiba; o uso do solo e o modo de vida urbano são dois importantes elementos a revelar os conflitos atinentes à relação entre a sociedade e a natureza naquela municipalidade. As políticas públicas locais estão deixando a desejar no sentido de prover ao conjunto da sociedade um ambiente adequado à sadia qualidade de vida que todos almejam alcançar.

\section{NOTA}

Este trabalho é derivado da Tese de doutorado do primeiro autor, apresentado ao programa de Pós-graduação em Meio Ambiente e Desenvolvimento da Universidade Federal do Paraná.

\section{REFERENCIAS}

$A B U L, S$. Environmental and health impact of solid waste disposal at mangwaneni dumpsite in Manzini. Journal of Sustainable Development in Africa, Swaziland. v. 2, n. 7, p. 64-78, 2010.

ASCHER, F. Os novos princípios do urbanismo. São Paulo: Romano Guerra, 2010. 103 p.

BANDARA, N. J. G. J. Environmental impacts with waste disposal practices in a suburban municipality in Sri Lanka. Journal Environment and Waste Management, UK. v. 6, n. 1 e 2, p. 107-116, 2010.

BAUMAN, Z. A ética possível num mundo de consumidores? Tradução de Alexandre Werneck. Rio de Janeiro: Zaharm, 2011. 272p. Título original: Does ethics have a chance in a world of consumers?

BONFANTI, F. A. La incorrecta gestión de los residuos sólidos urbanos y su incidencia en la calidad de vida de la población de Resistencia. Resistencia. Universidad Nacional del Nordeste. Comunicaciones Científicas y Tecnológicas, Argentina. 2004. 4 p. Disponível em: < http://www.unne.edu.ar/unnevieja/Web/cyt/c om2004/2-Humanidades/H-006.pdf> acessado em: 10 jan. 2013.

CHIEMCHAISRI, C.; JUANGA J. P.; VISVANATHAN, C. Municipal solid waste management in Thailand and disposal emission inventory. Environ Monit Assess. Springer: Science and Business Media, B.V. USA. 2007 (s.p). Disponível em: < http://www.ncbi.nlm.nih.gov/pubmed/174923 61 > acessado em: 10 out. 2012.

CROWLEY, D.; STAINES, A.; COLLINS, C. et al. Health and Environmental Effects of Landfilling and Incineration of Waste - A Literature Review. School of Food Science and Environmental Health, Dublin: Report paper 3. 2003. 284p. Disponível em: <http://arrow.dit.ie/cgi/viewcontent.cgi?article $=1002 \&$ context $=$ schfsehrep\&seiredir=1\&referer=http\%3A\%2F\%2Fwww.google. 


\section{RESÍDUOS SÓLIDOS NA ÁREA URBANA DE FAZENDA RIO GRANDE/PR: A PRODUÇÃO SOCIOAMBIENTAL DO ESPAÇO URBANO NA CIDADE PERIFÉRICA}

com.br\%2Fsearch\%3Foutput\%3Dsearch\%26scli ent\%3Dpsy-ab\%26rlz\%3D1C2GGGE ptPTBR449BR456\%26q\%3DHealth\%2Band\%2BEn vironmental\%2BEffects\%2Bof\%2BLandfilling\%2 Band\%2BIncineration\%2Bof\%2BWaste\%2B\%26 btnK\%3D\#search=\%22Health\%20Environmenta \%20Effects\%20Landfilling\%20Incineration\%20 Waste\%22> Acessado em: 6 jun. 2013.

DAVIS, M. Planeta favela. Tradução Beatriz Medina. São Paulo: Boitempo. 2006. 272p. Título original: Planet of slums.

FAZZO, L; SANTIS, M; MITIS, F. et al. Ecological studies of cancer incidence in an area interested by dumping waste sites in Campania (Italy). Ann Ist Super Sanità, Italy. v. 47, n. 2, p. 181-191, 2011.

FERREIRA, J. A; ANJOS, L. A. Aspectos de saúde coletiva e ocupacional associados à gestão dos resíduos sólidos municipais. Cad. Saúde Pública, Rio de Janeiro, v. 17, n. 3, p. 689 - 696, mai-jun, 2001.

FIGUEIREDO, P. J. M. A sociedade do lixo: os resíduos, a questão energética e a crise ambiental. Piracicaba: UNIMEP. 1994. 240p.

FIRKOWSKI, O. L. C. de F. Região metropolitana no Brasil: assim é se the parece. Campo Mourão. I Simpósio de Estudos Urbanos-SEURB. Desenvolvimento Regional e Dinâmica ambiental. Anais... Campo Mourão. Agosto de 2011. p. 29-31.

GESCHWIND, S. S.A.; STOLWIJK, A. J.; BRACKEN, $M$. et al. Risk of Congenital Malformations Associated with Proximity to Hazardous Waste Sites. American Journal of Epidemiology. USA. v. 135, n. 11 , p. 1197 - 1207, 1992. Disponível em:<http://www.jstor.org/discover/10.2307/3 702573 ? uid $=3737664$ \&uid $=2$ \&uid $=4 \&$ sid $=2110$ 1479280897>Acessado em: 20 out. 2010.

GOTTDIENER, M. A produção social do espaço urbano. Tradução de Geraldo Gerson de Souza. São Paulo: EDUSP. 2a ed. 2010. 310p. Título Original: The Social Production of Urban Space.

HELLER L. Resíduos sólidos domésticos e saúde: populações vulneráveis e situações de risco. In: Porto MFS, Freitas CM (Orgs). Problemas ambientais e vulnerabilidade: abordagens integradoras para o campo da saúde pública. Rio de Janeiro: Fiocruz, 2002. p. 99-124.

INSTITUO BRASILEIRO DE GEOGRAFIA E ESTATÍ́sTICA - IBGE (a). Sinopse do Censo Demográfico 2010.2 Disponível em:<www.ibge.gov.br $>$ Acessado em: 20 mai. 2010.

INSTITUTO PARANAENSE DE DESENVOLVIMENTO ECOCÔMICO E SOCIAL. (IPARDES). OBSERVATÓRIO DAS METRÓPOLES. Como andam as metrópoles: Região Metropolitana de Curitiba. 2006. 190p.

JACOBI, P. R. Desafios e reflexões sobre resíduos sólidos nas cidades brasileiras. In: SANTOS L, M. C.; DIAS, S. L. F. G. Resíduos sólidos urbanos e seus impactos socioambientais. (orgs.). São Paulo: IEE-USP, 2012. 82 p.

ALIL, A. Sustainable Development in Malaysia: A case study on household waste management. Journal of Sustainable Development, Canadian. v.. 3, n. 3. p. 91-102. Sep. 2010. Disponível em:

http://www.ccsenet.org/journal/index.php/jsd/ article/view/7323 > Acessado em: $10 \mathrm{dez}$. 2012.

JOSEPH, K.Solid waste dump sites to sustainable landfills. In: EnviroVision 2002. Centre for Environmental Studies, Anna University, Chennai, India. 2002. B1 (3) - p. 1$14 . \quad$ Disponível em: <http://www.swlf.ait.ac.th/UpdData/National/s olid\%20waste\%20dumpsites.PDF> Acessado em: 10 dez. 2012.

LIMA, J. D. Gestão de resíduos sólidos urbanos no Brasil. Campina Grande: ABES, 2001. 267p.

MENDONÇA. S.A.U. - Sistema socioambiental urbano: uma abordagem dos problemas socioambientais da cidade. IN: MENDONÇA, Francisco (org.) Impactos socioambientais urbanos. Curitiba: UFPR, 2004. 330p.

MORAES, L. R. S. Acondicionamento e coleta de resíduos sólidos domiciliares e impactos na saúde de crianças residentes em assentamentos periurbanos de Salvador, Bahia, Brasil. Cad. Saúde Pública, Rio de Janeiro. n. 23, Sup 4. p. 643 - 649, 2007. 


\section{RESÍDUOS SÓLIDOS NA ÁREA URBANA DE FAZENDA RIO GRANDE/PR: A PRODUÇÃO SOCIOAMBIENTAL DO ESPAÇO URBANO NA CIDADE PERIFÉRICA}

MUDZENGERERE, F. H.; CHIGWENYA, A. Waste management in Bulawayo city council in Zimbabwe: in search of sustainable waste management in the city. Journal of Sustainable Development in Africa, Pennsylvania. v. 14, $\mathrm{n}$. 1, p. 228-244, 2012.

MUÑOZ, S. I. S. Impacto ambiental na área do Aterro Sanitário e Incinerador de resíduos sólidos de Ribeirão Preto - SP: avaliação dos níveis de metais pesados. 131f. Tese (Enfermagem e Saúde Pública) - Escola de Enfermagem de Ribeirão Preto. PPG de Enfermagem e Saúde Pública. 2002.

NAKAYAMA, O.; OHKUMA, k. Mental Health Status of Municipal Solid Waste Incinerator Workers Compared with Local Government Office Workers. Industrial Health. n. 44, p. 613-618. 2006. Disponível em: <http://www.jniosh.go.jp/en/indu hel/pdf/ind health $44 \quad 4$ 613.pdf $>$ Acessado em: 8 jan. 2013.

NUNESMAIA, M. F. A gestão dos resíduos sólidos e suas limitações. Revista Baiana de Tecnologia- SSA. v. 17 , n. 1, p. 120-129. Jan/abr. 2002.

OLIVEIRA, C. F.; SANTOS, R. L. Mapeamento e aplicação de estatística espacial dos deslizamentos em Salvador - BA. Feira de Santana. V Simpósio Regional de Geoprocessamento e Sensoriamento Remoto. Anais... Feira de Santana-BA. 2011. p. 29-32. em: $<$

http://www.geonordeste.com/apresentacao_o ral/00281_113511.pdf> Acessado em: 05/10/2012.

ORSI, R. A. Convivendo Com O Lixo: A Vulnerabilidade socioambiental no bairro Jardim Graminha, Leme, São Paulo. Argentina. 2002.7 Congresso de Medio Ambiente. AUGM. Anais...La Plata Argentina. Maio. 2002. p. 1 20.

PROGRAMA DE LAS NACIONES UNIDAS PARA EL DESARROLHO (PNUD). Guia metodológica de capacitacion em gestion ambiental urbana para universidades de América Latina Y EL Caribe. New York. PNUD/UNOPS. 1997. 206p.

REYES, J. A. M. El problema de la basura en la Ciudad de México. Fundación de Estudios Urbanos y Metropolitanos. 2004. 82 p. disponível em: <http://www.paot.org.mx/paot docs/pdf/basu ra df.pdf> Acessado em: 11 dez. 2012.

RODRIGUES, A. M. Produção e Consumo do e no Espaço: Problemática ambiental urbana. São Paulo: Hucitec, 1998. 238p.

ROLNIK, R. Resíduos sólidos urbanos: repensando suas dimensões. In: SANTOS, L. M. C.; DIAS, S. L. F. G. Resíduos sólidos urbanos e seus impactos socioambientais. (orgs.). São Paulo: IEE-USP. 2012. 82 p.

SANTOS, M. A urbanização brasileira. 5a ed. São Paulo: Edusp. 2005.174p.

A natureza do espaço: Técnica e

Tempo, Razão e Emoção. 4ạ ed. São Paulo: USP. 2006. 259p.

THOMPSON, J.; ANTHONY H. The Health Effects of Waste Incinerators: 4th Report of the British Society for Ecological Medicine. Besen. British Society for Ecological Medicine, UK 2a ed. 2008. 71p. Disponível em: $<$ http://www.ecomed.org.uk/content/Incinerat orReport v3.pdf> Acessado em: 08 jan. 2013.

UNITED NATIONS
PROGRAMME - UNEP. Solid Waste
Management. UNITED NATIONS-HABITAT.
Meeting Development Goals in Small Urban
Centres: Water and Sanitation in the World
Cities. London:Earthscan Publications, 2006.
273p.

UNITED NATIONS ORGANIZATION. Urban Population, Development and the Environment, 2011. Disponível em: <http://www.un.org/en/development/desa/po pulation/publications/pdf/urbanization/urban wallchart 2011-web-smaller.pdf> Acessado em: 04 jun. 2013. 


\section{RESÍDUOS SÓLIDOS NA ÁREA URBANA DE FAZENDA RIO GRANDE/PR: A PRODUÇÃO SOCIOAMBIENTAL DO ESPAÇO URBANO NA CIDADE PERIFÉRICA}

VILLAÇA, F. Espaço intraurbano no Brasil. São Paulo: Studio Nobel/FAPESP: Lincoln Institute, 2001.373p.

WALDMAN, M. Lixo: cenários e desafios. São Paulo: Cortez, 2010. 231p.

YALAN, L; YUHUAN, R.; AIHUA, W. et al. Identifying the location and distribution of the open-air dumps of solid wastes using remote sensing technique. The International Archives of the Photogrammetry, Remote Sensing and Spatial Information Sciences. V. XXXVII. Part B8. Beijing. 2008. P. 67-72. Disponível em: $<$ http://www.isprs.org/proceedings/XXXVII/con gress/8 pdf/1_WG-VIII-1/13.pdf> Acessado em: 10 dez. 2012. 